\title{
The Eye of the CT Scanner: The story of learning to see the invisible or from the fluorescent screen to the photon-counting detector
}

\section{Das Auge des Computertomografen: Die Geschichte vom Sehenlernen des Unsichtbaren oder vom Fluoreszenzschirm zum photonenzählenden Detektor}

Author

Heinz-Peter Schlemmer

Affiliation

Abt. Radiologie, Deutsches Krebsforschungszentrum, Heidelberg, Germany

Key words

$\mathrm{CT}$, digital radiography, radiations, radiography

received 09.10.2020

accepted 17.01.2021

published online 18.03.2021

\section{Bibliography}

Fortschr Röntgenstr 2021; 193: 1034-1048

DOI 10.1055/a-1308-2693

ISSN 1438-9029

(c) 2021. Thieme. All rights reserved.

Georg Thieme Verlag KG, Rüdigerstraße 14,

70469 Stuttgart, Germany

\section{Correspondence}

Prof. Dr. med. Dipl.-Phys. Heinz-Peter Schlemmer Abt. Radiologie, Deutsches Krebsforschungszentrum, Im Neuenheimer Feld 280, 69120 Heidelberg, Germany Tel.: +49/62 21/422564

Fax: $+49 / 6221 / 422567$

h.schlemmer@dkfz.de

\section{ABSTRACT}

Roentgen's photographs with the "new kind of rays" triggered a worldwide storm of enthusiasm in all social circles. It was a stroke of luck that the photographic dry plates available to him were also sensitive to invisible X-rays. The discovery, research and utilization of $X$-rays are based on methods for making them visible, from fluorescent screens to photographic plates and digital $X$-ray detectors. From this point of view, this paper aims to outline the 125-year success story of X-ray imaging from its discovery to the recent development of photon-counting detectors. The scientific-historical view during the transition from the $19^{\text {th }}$ to the $20^{\text {th }}$ century reveals an impressive period of profound scientific and social upheaval in which revolutionary discoveries and technological developments led to enormous progress in medicine. The cross-fertilization of physics and medicine and their combination with inventiveness, engineering and entrepreneurial spirit created the impressive possibilities of today's imaging diagnostics. This contribution accompanies the Roentgen Lecture the author gave on November 13, 2020 in Roentgen's birth house as part of its inauguration and the closing ceremony of the $101^{\text {st }}$ Congress of the German Roentgen Society in Remscheid-Lennep.

Key Points:

- The development of computed tomography was a milestone in the methodological advancement of imaging with X-rays.

- In the detector pixel invisible X-rays are converted into digital electrical impulses, which the computer uses to create images.

- Photon-counting detectors could have significant diagnostic advantages for clinical applications.

\section{Citation Format}

- Schlemmer H, The Eye of the CT Scanner: The story of learning to see the invisible or from the fluorescent screen to the photon-counting detector. Fortschr Röntgenstr 2021; 193: $1034-1048$

\section{ZUSAMMENFASSUNG}

Röntgens Fotografien mit der „neuen Art von Strahlen“ Iösten einen weltweiten Begeisterungssturm in allen gesellschaftlichen Kreisen aus. Dabei war es ein Glücksfall, dass die ihm zu Verfügung stehenden fotografischen Trockenplatten auch für die unsichtbaren X-Strahlen empfindlich waren. Entdeckung, Erforschung und Nutzbarmachung von Röntgenstrahlen beruhen auf Methoden zur deren Sichtbarmachung, vom Fluoreszenzschirm über die Fotoplatte bis hin zum digitalen Röntgendetektor. Aus diesem Blickwinkel heraus möchte diese Arbeit die 125-jährige Erfolgsgeschichte der Röntgenbildgebung von der Entdeckung bis zur jüngsten Entwicklung photonenzählender Detektoren skizzieren. Die wissenschaftshistorische Betrachtung am Übergang des 19. zum 20. Jahrhundert offenbart eine eindrucksvolle Zeit tiefgreifender wissenschaftlicher und gesellschaftlicher Umbrüche, in der revolutionäre Entdeckungen und technologische Entwicklungen zu gewaltigen Fortschritten der Medizin führten. Die ge- 
genseitige Befruchtung von Physik und Medizin und deren Verquickung mit Erfindergeist, Ingenieurskunst und unternehmerischem Geschick schufen die eindrucksvollen Möglichkeiten der bildgebenden Diagnostik von heute. Diese Arbeit begleitet die Röntgenvorlesung, die der Autor am
13. November 2020 im Röntgen-Geburtshaus im Rahmen von dessen Eröffnung sowie des feierlichen Abschlusses des 101. Deutschen Röntgenkongresses in Remscheid-Lennep gehalten hat.
It was a Friday evening when Roentgen made his epochal discovery, which actually lasted only the blink of an eye. In the darkness, a fluorescent screen next to him suddenly lit up brightly. Purely by chance he was near a wrapped light-tight gas discharge tube with which he was experimenting on November 8, 1895 ( Despite the astonishment, or probably because of it, curiosity and the spirit of research drove him to immediately investigate the incomprehensible phenomenon and to examine it seriously according to the rules of the scientific method. The fluorescent screen lit up whenever he sent a voltage surge through the gas discharge tube. And it illuminated even when he put the most diverse opaque objects in front of it. Strange shadows cast from the inside of opaque objects were visible on photographic images. Roentgen then suspected that a "new kind of rays" must be spreading in his room, inaccessible to the eye. But he feared that people might say that "Roentgen has gone completely crazy" [1]. But when he photographed his wife's hand with this "new kind of rays" on Sunday, December 22, 1895, it was all set inexorably in motion:

- January 5, 1896: news release "A sensational Discovery" in the morning edition of the Viennese newspaper Die Presse. The news spread quickly in the daily press, on January 7 in the London Standard and Frankfurt newspapers, starting January 8 in American newspapers but not until January 9 in the Würzburger Generalanzeiger [2].

- January 9, 1896: telegraphic congratulations from Kaiser Wilhelm II and three days later, on January 12, personal presentation of Roentgen's discovery to the Kaiser in Berlin.

- January 23, 1896: public lecture (his only one!) in the packed lecture hall of the Physical Institute of the Würzburg PhysicalMedical Society before an audience from all circles of science and society. The proposal of the anatomist Albert Kölliker to rename the "X-rays" to "Roentgen rays" was greeted with cheers.

- January 24, 1896: first X-ray image for an operation (double toe) in Vienna [3].

Physicians were interested in the inside of the body, the Kaiser probably more interested in the interior of weapons. But Wilhelm Conrad Roentgen could not have anticipated all this on the evening of his discovery, November 8, 1895. When asked later what he was thinking, he said, "I was not thinking, I was investigating" [4]. His working methods were characterized by a high degree of scientific diligence, patience and perseverance. Roentgen's enthusiasm for research is evident from the fact that even on that Friday evening he was alert and focused enough to take note of this momentary phenomenon, rather than dismissing it as incidental. Persistent experimentation followed, and as early as Satur-

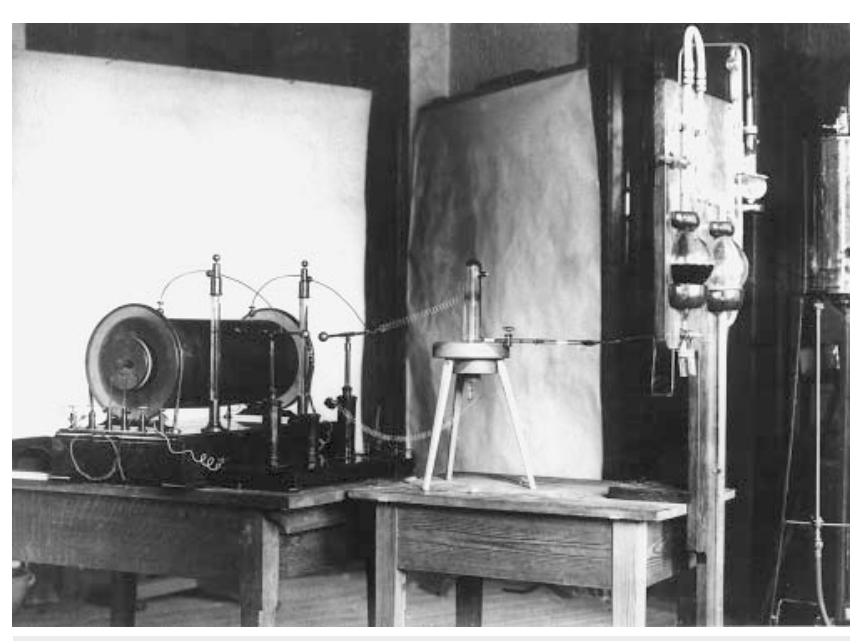

- Fig. 1 Apparatus which Roentgen used to discover X-rays: Rap's vacuum pump, Rühmkorff's spark inductor and a Hittorf gas discharge tube. (๑ Deutsches Röntgen-Museum Remscheid). [rerif]

day of Christmas week, December 28, 1895, he submitted his first paper, "On a new Kind of Rays." Obviously, his experiments and photography of his wife's hand had kept him very busy even over Christmas Eve on Tuesday and the two Christmas holidays Wednesday and Thursday. And already on the following Wednesday, January 1, 1896, New Year's Day, he sent his first announcement to friends and colleagues.

Despite his obvious enthusiasm, Roentgen maintained his scientific soberness. He found that after his discovery there was "astonishing hoopla" (after only one year there were more than 1100 publications on the subject, incomparable in scale). Despite requests and proposals, he deliberately refrained from patenting his discovery because, in his opinion, inventions and discoveries should belong to the general public and not to individual companies. He donated the 50000 crown prize money from his Nobel Prize in 1901, the first ever for physics, to the University of Würzburg for the promotion of young scientists. He preferred to go to the mountains than to conferences; he loved observing nature, was an enthusiastic mountaineer, hunter and - photographer.

His X-ray photographs quickly spread around the world and changed medical diagnostics so rapidly that, as early as 1923 , the surgeon Ferdinand Sauerbruch complained to Roentgen that his invention had led doctors to rely too much on the new procedure and no longer examine their patients closely. X-ray technology had been decisively improved shortly before by the invention of the glow-cathode high-vacuum X-ray tube by William David Coolidge (1873-1975) ( $\triangleright$ Fig. 2). The technology made it possible 


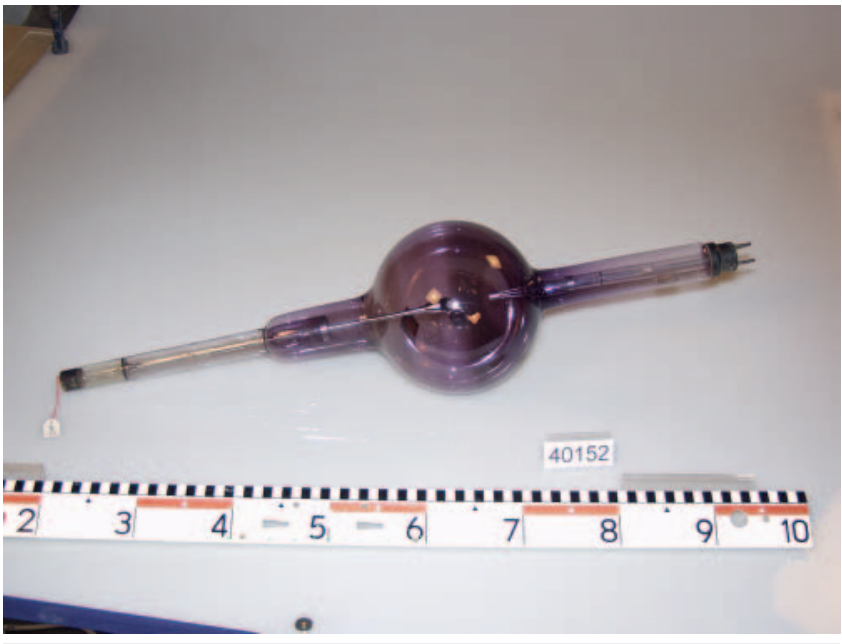

- Fig. 2 After the first successful practical tests in July 1914, AEG in Berlin took over production of the new Coolidge X-ray tube in Germany. (@ Deutsches Röntgen-Museum Remscheid). [rerif]

for the first time to regulate voltage and current, and thus the quality and intensity of the $\mathrm{X}$-rays, independently of one another. After the initial introduction in December 1913 and the first practical application by Heinrich Albers-Schönberg (1865-1921) in 1914 in Hamburg, the path was opened to reproducible medical imaging with X-rays. Coolidge had met Roentgen personally in Leipzig ("Although he does not appear very friendly, he appears very capable") [5]. In 1928, the German physicists Hans Geiger (1882-1945) and Walther Müller (1905-1979) developed the counting tube named after them, which could be used to detect particle beams and $\mathrm{X}$-rays. Thus equipped with the proper measuring instruments to detect the invisible rays, research into radiation applications in medicine was also able to develop further. The success story of the unfolding medical radiation-related subjects of radiology, nuclear medicine and radiotherapy took its course.

The development of computed tomography (CT) by Godfrey Newbold Hounsfield (1919-2004) in the $1970 \mathrm{~s}$ was a milestone in the methodological advancement of imaging with the new $X$-rays. It was the very first method of generating cross-sectional images, which thus allowed superimposition-free views of the inside of the body without even touching it; this method has continued impressive development even to the present. Contour sharpness, image contrast and spatial resolution have been increased into the isotropic sub-millimeter range; the acquisition time per slice has been reduced to a millisecond time scale; the scan length for whole-body images has been extended to two meters, while at the same time the dose requirement has been significantly reduced. The amazing increase in the performance of $\mathrm{CT}$ systems is attributed to technological advances in the following individual components:

1. The X-ray tube, i. e., its increased performance with improved anode material, reduced focal point size, improved energy spectrum, and extended beam time;

2. The gantry with its increased precision and shortened rotation time;
3. Detector arrays with their increasing number of lines, as well as

4. Improved image reconstruction techniques, such as iterative reconstruction or, more recently, deep learning reconstruction.

On the other hand, the smallest but sometimes most important and physically and technologically most fascinating component of image generation, i. e.

5. The detector pixel, the actual sensor for the $\mathrm{X}$-rays. In these small elements, a few millimeters to sub-millimeters in size, the crucial process of converting invisible $X$-rays into measurable electrical impulses takes place, from which the image visible to the eye is calculated. What the retina is to the eye, the detector array is to the computer tomograph. And just as our brain generates an informative image of the world in the light of the rainbow wavelengths of the sun $(380-780 \mathrm{~nm})$ from the primary data of the rods and cones, the image processor calculates an informative image of objects in the light of the wavelengths of an X-ray tube (approx. 0.01$0.1 \mathrm{~nm}$ ) from the raw data of the detector pixels.

Physicians immediately recognized a great diagnostic potential for the whole of medicine from an X-ray photograph of the hand. The rapid development of improved methods for visualizing $X$-rays, from fluorescent screens to photographic plates and digital X-ray detectors, was of fundamental importance for the continued success of medical $X$-ray imaging, since it was only these methods that enabled further research and utilization of this "new type of rays". "The retina of the eye is insensitive to our rays," Roentgen emphasized already in his first announcement [6].

This paper aims to trace the success story of X-ray imaging from this aspect, i. e. from the point of view of the detection of $\mathrm{X}$-rays. Following the path of the history of science reveals a period of profound scientific and social upheavals. At the transition from the 19th to the 20th century, revolutionary discoveries occurred in physics and medicine, whose cross-fertilization and amalgamation with inventiveness, engineering and entrepreneurial skill led to astonishing advances in medical imaging diagnostics. There is no claim to completeness here, as the author is a radiologist and physicist, not an historian. Numerous historical details can be found in the literature, e. g. in two excellent books published on the occasion of the 100th anniversary of the discovery of $\mathrm{X}$-rays $[7,8]$.

In the human eye, our visible light is detected by a thin sensor, the retina, which is about $200 \mu \mathrm{m}$ thick and about $22 \mathrm{~mm}$ in diameter, representing a matrix of about 120 million pixels, or photoreceptors, consisting of the rods and cones, each with a diameter of about $2 \mu \mathrm{m}$. These cells contain large amounts of densely stacked rhodopsin, a protein that absorbs electromagnetic radiation with wavelengths from 380 to $780 \mathrm{~nm}$. The absorption triggers a 3-dimensional conformational change in the protein, which leads to an enzymatic cascade reaction, which in turn causes the $\mathrm{Na}+$ channels of the cell membrane to be closed with a consecutive sudden change in membrane potential. The action potentials thus triggered transmit a chain of (digitized) nerve impulses to the central visual centers of the brain, where the image of our en- 
vironment is ultimately formed. Similarly, CT detectors and flat panel detectors of digital X-ray equipment consist of a matrix of pixels, approximately $200 \mu \mathrm{m}$ to $1 \mathrm{~mm}$ in size, in which absorption of incident electromagnetic waves also takes place, only of a different wavelength. Unlike visible light, X-rays lead to ionizing effects due to their much higher energy, i. e. they release electrons predominantly from the inner shells around the atomic nucleus, and a cascade of further ionizations subsequently leads to the release of electrons from increasingly further removed shells. This causes electrical and chemical reactions that trigger measurable effects, such as luminescence of fluorescent screens, blackening of photographic films, light flashes in scintillators, and electrical current and voltage changes in semiconductor photodiodes. In modern semiconductor detectors, the released electron cascades are drawn off directly to an anode and forwarded directly as a digitized current pulse to the central image computer, where the image of the body being X-rayed is created. Any method of visualizing high-energy electromagnetic radiation relies primarily on interaction with electrons, whether in an organic protein or an inorganic solid.

When Roentgen was alive, however, the atomic structure of matter was still unknown. In 1895, Roentgen lived in the familiar mechanistic world view, the so-called Newtonian world view, also referred to in retrospect as the "classical" world view. Based on seemingly unshakable beliefs in a mechanistic order, physical processes were understood like clockworks ticking in absolute space and in an omnipresent flowing time, whose parts had to be found and cataloged only bit-by-bit. Max Planck (1858-1947), one of the later revolutionaries of physics, had even been advised against studying physics at all in 1874, since "almost everything in this science has already been researched" [9]. But toward the end of the 19th century, unusual observations began to accumulate that inexorably shook the old beliefs. In addition to the exploration of visible spectral colors, it was mainly the discovery of invisible "rays", such as "caloric rays", "deoxygenating rays", "radio waves", "X-rays and "radio activity", which shook the mechanistic view of the world and led to bizarre ideas such as curved space times, black holes, spooky remote effects, materialization of energy waves or random events. Albert Einstein (1879-1955) published his sensational special and general theories of relativity in 1905 and 1915, respectively, and Werner Heisenberg (19011976), Erwin Schrödinger (1887-1961), and Max Born (18821970) formulated their sometimes seemingly grotesque quantum mechanics in 1925 and 1926 . Within only about 30 years, the long-familiar physical world view had radically changed. And even if to this day people are still struggling, sometimes desperately, to understand these ideas, some of which seem absurd, these theories are nevertheless the most successful in the history of physics. In industrialized countries, many developments based on relativity and quantum physics have led to useful applications that are now commonplace, such as all digital telecommunications, GPS tracking of navigation systems, lasers with their manifold uses in technology and medicine, and, of course, X-ray imaging with high-sensitivity flat-panel detectors and photoncounting detectors, MR tomography with superconductivity and radio waves to new, futuristic-sounding technologies such as quantum cryptography and quantum computing. Roentgen's dis-

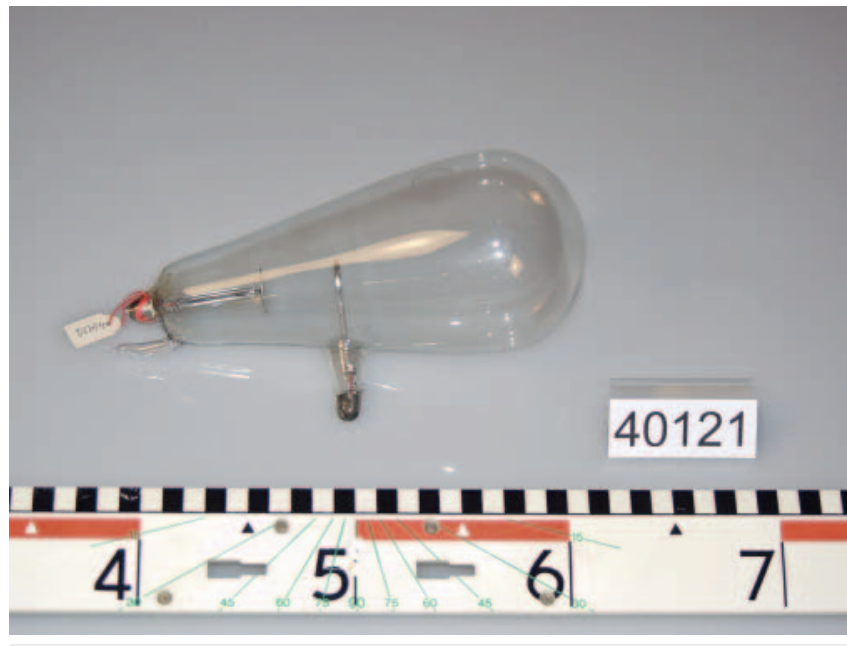

- Fig. 3 Pear-shaped Crookes-Hittorf tube. (@ Deutsches RöntgenMuseum Remscheid). [rerif]

covery was a major impetus for these changes, even if he did not realize it (and probably did not want it). Subsequently, completely new terms emerged, such as braking radiation, K-shell, quantum jump, Compton effect, pair formation, etc.

The economic potential of electricity had been recognized by the end of the 19th century, the end of the Industrial Revolution era, and consequently, technical applications were intensively developed. In particular, it had become possible to generate artificial light with electricity, which represented a tremendous beneficial advance with accompanying great commercial potential. This meant that increasingly powerful technologies with high luminosity and low heat loss had to be developed. In Roentgen's day, research into the visual luminous phenomena of gas discharge tubes, called cathode ray tubes was in vogue. Gas discharge tubes are gas-filled and differently evacuated glass tubes of various designs, named after their respective designers, such as Geissler, Hittdorf, Crooke, or Lenard tubes. Like many of his colleagues, Roentgen used such a gas discharge tube for his research ( Fig. 3).

Fused into these low-pressure tubes were two metal electrodes between which, when a sufficiently high voltage was applied, electrical discharges with impressive luminous phenomena could be produced. The fascinating luminous phenomena arose most brightly near the negatively charged electrode, the cathode, hence the term "cathode rays". The application of the required high electrical voltage was only possible because of a pioneering invention by Heinrich Daniel Rühmkorff (1803-1877), which has unfortunately been somewhat forgotten. He had developed the crucially important instrument with which pulsating high voltages of several hundred thousand volts could be generated from low DC voltages of a few volts. Only then could the discharge between the two electrodes be triggered. Undoubtedly, such experiments must also have continuously produced this invisible "new kind of rays". As early as 1879 , while experimenting with cathode ray tubes, William Crookes (1832-1919) was annoyed that nearby photo plates showed haze, and even the later Nobel Prize winner JJ Thompson (1856-1940), who discovered the electron in the 
cathode rays in 1897, had dismissed suggestive phenomena as accidental and incidental $[10,11]$. In retrospect, a first "X-ray" image was taken completely unwittingly on February 22, 1890. At the University of Pennsylvania, the physicist Arthur Goodspeed (1860-1943) and photographer William. N. Jennings (18601946) took photographs of high voltage discharges. After that, they were still experimenting with Crookes discharge tubes where photographic plates happened to lie nearby. The development of these photographic plates revealed inexplicable roundish shadows, but this observation was not pursued. After Roentgen's publication, Goodspeed then immediately realized that round structures in the photographs must have been X-ray images of coins that happened to be on the plate; he was able to immediately reproduce this result [12].

Roentgen likewise began to study these cathode rays. His special interest was the attempt to examine the cathode ray directly outside in the low-pressure tube, i. e. in the open air [13]. The Heidelberg physicist Philipp Lenard (1862-1964) had already developed a special gas discharge tube for this purpose with a thin aluminum foil through which the cathode ray could penetrate to the outside, the so-called "Lenard window". In his Würzburg experiments, on the other hand, Roentgen investigated the question of whether the cathode ray could possibly also penetrate the glass wall itself directly. To detect a very weakly expected beam outside the tube, he worked in complete darkness and shielded the brightly shining tube with black cardboard. But then suddenly something very strange happened during one of his experiments: “... (one can see a) paper screen coated with barium platinocyanide light up brightly with every discharge, fluorescing” [14]. This had happened to be near the gas discharge tube and lit up as if by magic. The fluorescence would have caused only the visible glow of the cathode ray in the gas discharge tube, which he had nevertheless completely suppressed by the black cardboard. Thereupon, Roentgen apparently abandoned his original plan of finding cathode rays behind the glass wall of the tube, and turned his full attention on this inexplicable phenomenon. Presumably, it was precisely the inexplicability of this that sparked his feverish scientific curiosity. An extraordinary degree of determination, perseverance, observation and judgment drove him to get to the bottom of this phenomenon with numerous experiments in a short time. The ability of the new "rays" to penetrate opaque materials, as well as the human hand in particular, were extraordinarily impressive. Just seven weeks after his discovery, he had completed his epoch-making paper "On a new Kind of Rays (Preliminary Announcement)", so that he was able to submit it on December 28, 1895 to the secretary of the Physikalisch-medicinische Gesellschaft zu Würzburg (Würzburg Physical Medical Society) for publication in the society's proceedings shortly before the turn of the year.

Moreover, with his work he initiated another epoch-making discovery, which was to become not only of great importance for the further development of radiation medicine but also of the greatest global political significance. On January 20, 1896 Henri Becquerel (1852-1908) learned of Roentgen's announcements only four weeks later. Becquerel experimented with uranium salts that could be made to fluoresce by sunlight. He then investigated whether this fluorescence might also be associated with the emis- sion of these invisible X-rays. He found his suspicions confirmed when he observed that photographic plates were blackened even when he had previously packed the fluorescent uranium salts light-tight (much like Roentgen did with his tubes). But a little later and by chance he observed to his astonishment that this blackening occurred even if the uranium salts had not previously been excited to fluorescence by sunlight. Obviously, the uranium salts were also able to emit invisible rays spontaneously on their own. From the end of 1898, Marie (1867-1934) and Pierre Curie (1859-1906) devoted themselves to the study of this "Becquerel radiation", and they made sensational discoveries. Marie Curie coined the term "radioactivity" and received two Nobel Prizes for her groundbreaking research, one for physics in 1903 and the other for chemistry in 1911; she shared the first prize with her husband Pierre and Henri Becquerel.

It is important to remember that at that time the structure of the atom was not even rudimentarily known, and even the existence of atoms was still a controversial subject. The electron was only discovered two years after Roentgen's X-rays, in 1897 by Joseph John Thomson (1856-1940), likewise in cathode rays. Sixteen years later, in 1911, Ernst Rutherford (1871-1937) discovered the existence of the atomic nucleus in his scattering experiments with these electrons. And it was not until 1913, almost twenty years after Roentgen's discovery, that Niels Bohr (18851962) developed the familiar atomic model, in which electrons surround the atomic nucleus on very specific shells. No physicist was aware of this atomic structure of matter when Roentgen observed the mysterious illumination of his fluorescent screen.

The fluorescent screen used by Roentgen consisted of cardboard coated with finely powdered greenish-yellow crystals of barium platinocyanide, covered with black paper. It was actually pure coincidence that not only light but also X-rays make this material fluoresce. However, the luminosity of these short-lived fluorescence phenomena was so low that it was difficult for Roentgen to observe the penetration capacity of these unknown $\mathrm{X}$-rays more exactly and, above all, to precisely investigate the dependency of material and distance. But as an enthusiastic amateur photographer, Roentgen quickly discovered that photographic dry plates were also proven to be sensitive to X-rays. "One is able to fix certain phenomena, which makes it easier to rule out illusions; and wherever I could, I checked every important observation that I made with my eye on the fluorescent screen by taking a photograph" [6].

It was also a stroke of luck that storable photographic dry plates with increased light sensitivity were available to Roentgen at the time. The method of photography ("light drawing") had been developed in the course of the 19th century and continuously improved. The industrialization of photography had already begun in 1888, and the first roll film camera was manufactured on a large scale, the Kodak No. 1 [15]. Roentgen thus took the opportunity to photograph the radiolucency of various objects and thus documenting and studying the phenomenon in scientific detail. In addition, the shadow photographs produced by the $X$-rays had a very special aesthetic appeal that greatly impressed not only scientists and medical professionals, but also the general public. One of Roentgen's most sensational initial images was 


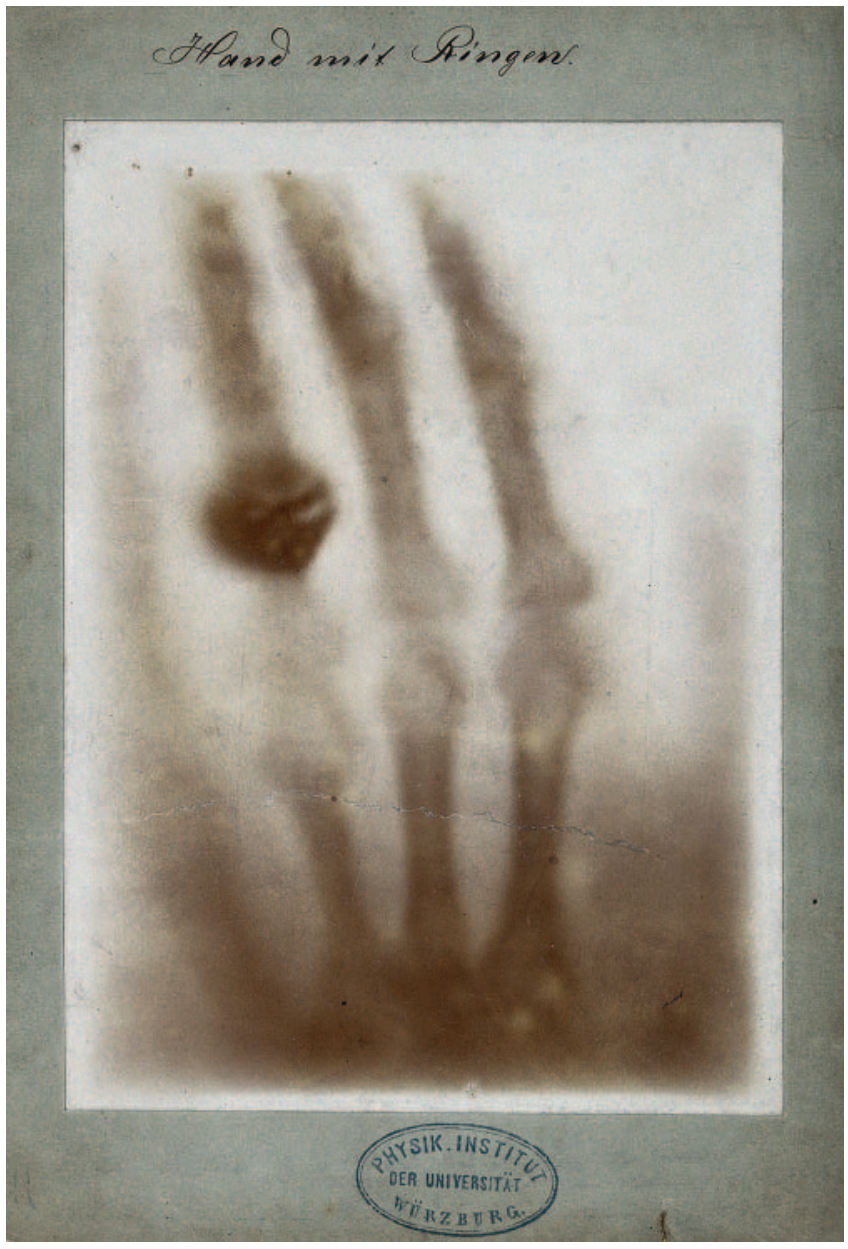

- Fig. 4 Radiography of Anna Bertha Roentgen's hand (1839-1919). (@ Deutsches Röntgen-Museum Remscheid). [rerif]

certainly that of his wife Bertha's hand, taken on December 22, 1895 ( $\triangleright$ Fig. 4).

The discovery of X-rays also brought photography into a new dimension. The invisible inner structures of objects and materials could be made visible and fixed in time. The new photographs thus provided insights into a previously completely inaccessible world ( $\triangleright$ Fig.5). In their appearance and way they were exposed, the new X-ray images resembled photograms from the early days of photography. It is not surprising that photographers also saw new possibilities for expanding their artistic activity. Among the first publications in 1896 was an article in the British Journal of Photography [16]. Even in medical circles there was a search of a name for the "new type of photography" with X-rays; various technical terms were discussed, including "X-ray photography" or simply "new photography" [17]. The teasing job title "photographer" haunts radiologists even today.

Roentgen attributed the luminescence of the fluorescent screen to the fact that it had to be triggered by unknown rays emanating from the gas discharge tube. As the point of origin of these presumed rays, which he himself christened "X-rays", he quickly suspected the faintly luminous inner wall of the glass tube, where the cathode rays struck the glass and produced a

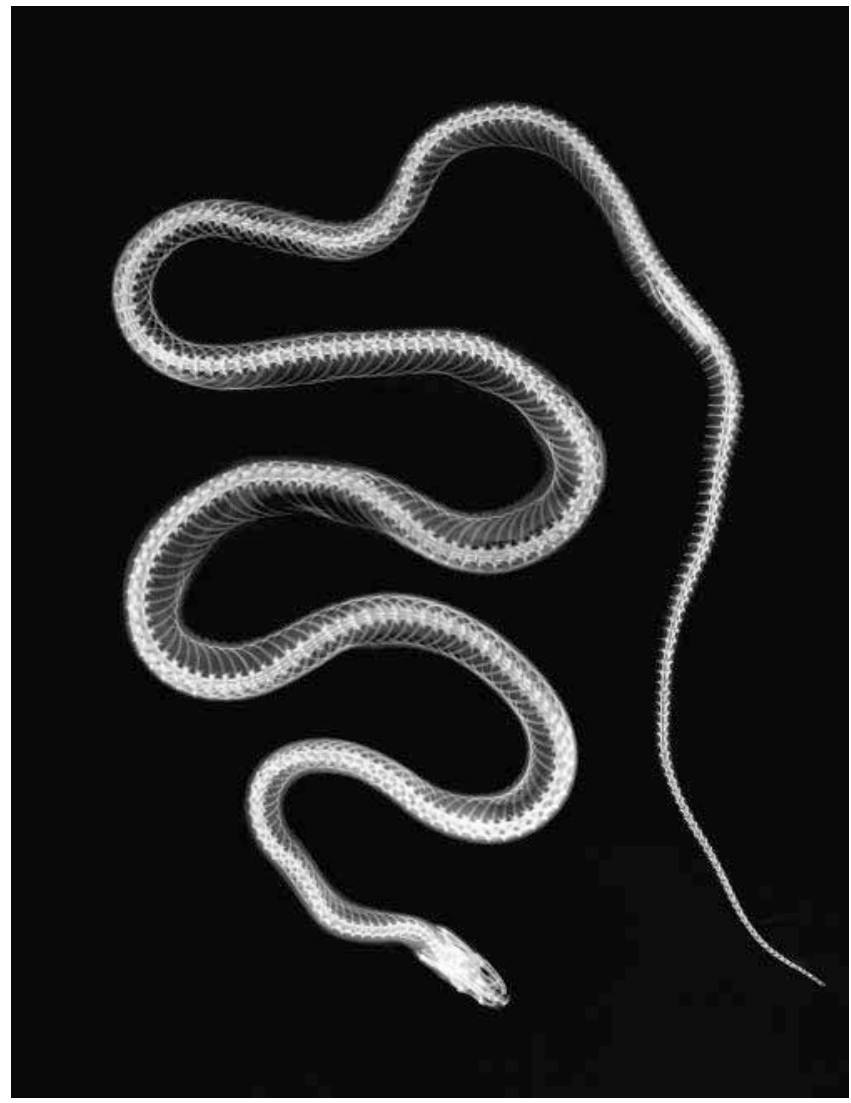

- Fig. 5 Radiography of a snake. From: Eder JM. und Valenta E. Versuche über Photographie mittelst der Röntgen'schen Strahlen (Trans. Experiments in Photography using X-rays). Herausgegeben mit Genehmigung des K. K. Ministeriums für Cultur und Unterricht von der K. K. Lehr- und Versuchsanstalt für Photografie und Reproductíons-Verfahren in Wien, Wien, R. Lechner \& Halle, Wilhelm Knapp, 1896. (Trans. Published with the permission of the K. K. Ministry for Culture and Education, Vienna, R. Lechner \& Halle, Wilhelm Knapp, 1896) (@ Archiv Deutsches Röntgen-Museum Remscheid). [rerif]

faintly visible fluorescence there. He had also paid particular attention to this location, as he suspected that the cathode rays penetrated through the glass wall. "The $\mathrm{X}$-rays therefore emanate from the point where, according to various researchers, the cathode rays strike the wall" [18].

However, the physical nature of this "new kind of rays" was completely unclear to him. Based on the assumption that the $X$-rays emanated from the point on the glass wall of the tube where the cathode rays hit them and cause them to fluoresce, Roentgen initially considered that these could be invisible rays of light, since the existence of invisible light components in sunlight was already known at that time. As early as 1800 William Herschel (1738-1822) had observed a particular warming of a thermometer beyond the red end of the rainbow spectrum, which led him to infer the existence of "caloric rays" in sunlight (today: infrared rays). A year later, Johann Wilhelm Ritter (1776-1810) observed that the blackening of silver chloride paper was particularly effective just outside the visible rainbow spectrum, that is, beyond its other, violet end. He also concluded the existence of rays in sun- 
light inaccessible to the eye and called them "deoxidizing rays", later renamed "chemical rays" (today: ultraviolet rays). (Sunlight reaching the Earth's surface consists of approximately $50 \%$ infrared, $40 \%$ visible, and $5 \%$ ultraviolet light.) Thus Roentgen had been on the right track early on when he suspected that X-rays might be a form of chemical radiation (only about one order of magnitude separates the wavelength range of UV rays at 380$100 \mathrm{~nm}$ from that of X-rays at $10 \mathrm{~nm}-1 \mathrm{pm})$. But he was forced to drop his initial assumption again, because he could not prove any effects of refraction, reflection nor polarization typical for waves. ("In this respect, one immediately encounters serious doubts", [19]). By experimenting with deflecting magnets, he ruled out the hypothesis that $\mathrm{X}$-rays could be high-energy cathode radiation. Thereupon he suspected that the X-rays could be longitudinal aether oscillations, "....although I am well aware that the given explanation still needs further substantiation” [19]. This shows Roentgen's excellent, consistently scientific way of working, making claims only on the basis of reproducible observational data.

Electromagnetic waves had been detected in 1886 only nine years before Roentgen's experiment, by Heinrich Hertz (18571894 ) in Karlsruhe (although predicted as early as 1864 by James Clerk Maxwell (1831-1879)). Hertz generated high-energy sparking in the air between two metal spheres standing close to each other by applying high electrical voltages, incidentally also with the help of a Rühmkorff spark inducer, which was later also supposedly used by Roentgen to discover his X-rays. With his experimental setup, he proved that these sparks were able to trigger comparable sparking between spatially distant metal spheres. He thus concluded that rays released by the first spark had to spread through space, which, arriving at the location of the distant pair of spheres, triggered corresponding sparking there. He was able to demonstrate the wave character of these rays with special experiments that revealed their wave-typical properties such as reflection and diffraction. He then called these rays "radio waves" (and thus heralded "radio"). Incidentally, Heinrich Hertz had also experimented with cathode ray tubes and discovered that they could penetrate a thin metal foil. His student Philipp Lenard advanced his experiments further and developed corresponding gas discharge tubes with his "Lenard window" [20].

After Roentgen's discovery, many physicists searched for effects of reflection, refraction, diffraction and polarization of $\mathrm{X}$-rays to prove their possible wave character, but initially also in vain. In retrospect, this is also understandable, since $X$-rays have a very short wavelength $<10 \mathrm{~nm}$, and thus wave effects only occur on an atomic scale, requiring highly sophisticated experiments to detect them. Heinrich Hertz could only succeed in proving the wave character of his generated "radio waves" because their wavelength of about $50 \mathrm{~cm}$ was about 7 orders of magnitude longer than that of X-rays. It was not until 1912 that Max von Laue (1879-1960) presented diffraction patterns of crystals, thus proving that $\mathrm{X}$-rays are indeed electromagnetic waves with very short wavelengths. Einstein wrote to him "Your experiment is one of the most beautiful things physics has seen". In addition to the Nobel Prize in Physics in 1914, Max von Laue received many other honors for his discovery, including the Roentgen Plaque in Remscheid, Roentgen's birthplace, in 1952. The method came to

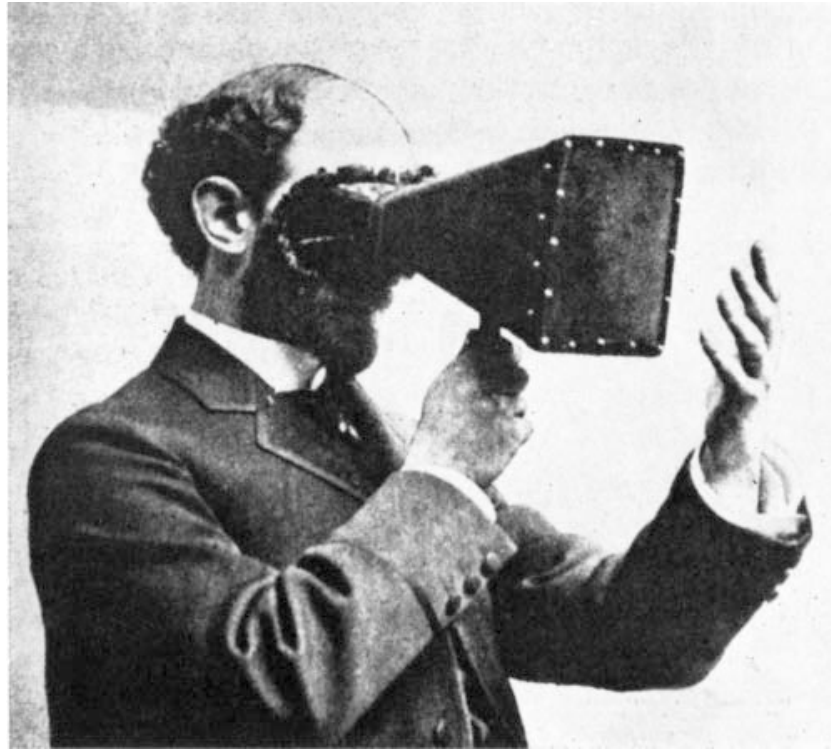

- Fig. 6 Early fluoroscope using Edison's design (๔ Deutsches Röntgen-Museum Remscheid). [rerif]

application maturity through the fundamental idea of Lawrence Bragg (1890-1971) on reflection of X-rays at reticular planes ("Bragg equation") together with the spectrometer development of his father William (1862-1942). Both of them made the method one of the most important standard methods for elucidating the atomic structure of crystalline materials. In 1915, father and son shared the Nobel Prize for physics. As a result, X-ray diffraction led to discoveries, some of which were groundbreaking. Thus, based on the X-ray diffraction patterns of biochemist Rosalind Elsie Franklin (1920-1958), the double helix structure of DNA was deciphered in 1953 by James Watson (born 1928) and Francis Crick (1916-2004). Due to her tragic death, the Nobel Prize bypassed Franklin and went to Watson and Crick alone. Ada Yonath (born 1939) used the method to decipher the molecular structure of the ribosome, the cell's fundamentally important protein factory, a discovery so groundbreaking that she received the Nobel Prize.

But let's take another step back in the historical development of X-ray detectors. Impressed by Roentgen's photographs, people began to think about how the sensitivity of photographic films to $X$-rays could be increased. In his search for new business opportunities, Thomas Edison, known as the "inventor" of the carbon filament lamp (light bulb) with his 1880 patent, was also looking for materials to make X-rays more sensitive to exposure. In 1896, he succeeded in demonstrating that calcium tungstate glowed six times brighter than barium platinocyanide when exposed to $X$-rays. The "fluoroscopes" he developed subsequently enabled the unaided eye to view the shadow images of bones in an impressive way. This allowed a large audience to enjoy these spectacles at fairs, and the method was widely used [21] (> Fig. 6).

Photographs of the shadow images undoubtedly offered great advantages for research and medical application. The permanent images could be documented, disseminated and thus communicated. However, the acquisition time for X-ray images was initially 
as much as two hours. However, as early as February 1896, Michael Pupin (1858-1935) was able to make excellent X-ray photographs even with short exposure times of a few seconds by placing a barium platinocyanide fluorescent screen on the inside of the photographic plate. The photographic effect of X-rays could thus be enhanced by exploiting the luminescence of phosphors that, excited by the $\mathrm{X}$-rays, glowed in visible light and thus additionally exposed the photographic plate. At the same time, Charles Henry (1859-1926) identified zinc sulfide as a phosphorescent phosphor; as mentioned above, Thomas Edison also identified calcium tungstate in this regard. The engineer Max Levy (1869-1932) further increased the sensitivity of X-ray photographs by placing a photographic plate coated on both sides between two fluorescent screens. Further improved intensifying screens with e. g. zinc silicate were used as X-ray fluorescent materials until the $1960 \mathrm{~s}$.

In X-ray photography, silver halides (mainly silver bromide, silver chloride) are applied to plates or plastic films. X-rays release metallic black silver from this light-sensitive layer when they strike it, and energize an electron of the halide (e. g. bromine, chlorine) and transfer it to the positively charged silver ion, which is thereby reduced to a neutral, metallic silver atom. The subsequent "development" and "fixing" with chemical agents transforms the initially invisible latent image into a permanent image by enlarging the site of silver formation and making its surroundings insensitive to light. Introduction of rare-earth phosphors in 1970 further increased $\mathrm{X}$-ray absorption and light output. Blue-emitting yttrium oxysulfide $\left(\mathrm{Y}_{2} \mathrm{O}_{2} \mathrm{~S}\right.$ [Tb]) was found to be a phosphor with a resolving power 2 line pairs per millimeter $(\mathrm{Lp} / \mathrm{mm})$ higher than conventional calcium tungstate films, and required half the dose for the same resolution. In addition to higher spatial resolution, shorter exposure times were also possible, whereby the dose requirement could be reduced by half with the same definition [22]. Subsequently, the resolution, contrast and dose requirements of X-ray films and fluoroscopic screens have been steadily increased with new phosphors and substrates, new film-foil combinations, improved $\mathrm{X}$-ray tubes and sophisticated exposure techniques.

However, the dynamic range of conventional X-ray films is low, which easily results in incorrect exposures and unnecessary radiation exposure. The development of storage phosphor image plates decisively increased dynamic range. Technology has led to an improvement in resolution and contrast while reducing the dose required and increasing the robustness against incorrect exposures. In the storage phosphor image cassettes there is a plastic carrier film with an approximately $1-2 \mathrm{~mm}$ thin phosphor layer made of doped barium fluoride applied to it. When they release energy, X-rays permanently shift electrons in the phosphor layer and thus imprint their intensity on a latent image. The actual and visible image is later "read out" by pixel-by-pixel scanning with a laser with a wavelength of $500-700 \mathrm{~nm}$ by inducing photoluminescence and measuring it using a photomultiplier and storing it digitally. Compared to chemical development of conventional films, the readout process offers the advantage of being significantly shorter and easier to manage. In addition, the imaging plate can be reused several thousand times after being erased by light. Another advantage is that the imaging plates are installed in a cassette design with the same dimensions as conventional X-ray films, so that they can be used with conventional X-ray equipment without adaptation.

The illumination of luminescent screens is caused by electrons being temporarily lifted to higher energy levels by absorbing the energy of incident $X$-rays, and then releasing this energy as light when they return to their resting state. Depending on the material, there is either a very short afterglow (fluorescence) or a delayed, longer afterglow (phosphorescence). X-ray examinations with fluoroscopy equipment were significantly improved in the $1960 \mathrm{~s}$ with the development of X-ray image intensifiers and image converters. The light primarily generated by the luminescent scintillator screen strikes a thin photocathode and releases electrons there, which in turn are accelerated towards an anode. There the electrons are focused on a luminescent scintillator screen and converted into light that can be visually observed.

The further development of $\mathrm{X}$-ray detectors was to be significantly influenced by another phenomenon that had not been understood until then. In 1887, Heinrich Wilhelm Hallwachs (1859-1922), an assistant to Heinrich Hertz, had discovered during his spark experiments with an arc lamp that light (UV rays) could electrically charge the metal surface of an electrode. Initially called the Hallwachs effect, it was renamed the photoelectric effect. In March 1896 Roentgen reported that he had already observed a similar phenomenon at the time of his first publication, namely the discharge of electric bodies by X-rays. But the explanation of the phenomenon had to remain in the dark, since, as already mentioned, neither electrons nor the atomic structure of matter were known at the time. Ten years later, in 1905, Albert Einstein (1879-1955) explained the photoelectric effect by stating that light, or electromagnetic waves, consisted of small particles called "light quanta" that could knock electrons out of the surface of a metallic substance. Until then, electromagnetic waves had been considered, as the name suggests, as spatially extended waves, resembling water or sound waves. In 1900 Max Planck had felt compelled to break up electromagnetic waves into energy quanta in order to explain the phenomena of radiation emission from hot bodies (cavity radiation), which had not been understood until then; but he had assumed that it was only a theoretical construct that he would abandon as soon as he understood the true relationships more deeply. But the discovery of the photoelectric effect and its causal explanation by Albert Einstein consolidated this idea of quantization of electromagnetic radiation. Einstein went down in history as the founder of the quantum theory of radiation and received the Nobel Prize in Physics in 1921 for "his services to theoretical physics, especially for his discovery of the law of the photoelectric effect". The understanding of the photoelectric effect and the targeted development of special X-ray-sensitive materials, i. e. electromagnetic waves with wavelengths between $1 \mathrm{pm}$ and $10 \mathrm{~nm}$, is fundamental for the development of increasingly sensitive detectors including photon-counting detectors.

Another important physical effect that significantly influences the detection of X-rays and the quality of medical images was discovered still later. In 1922, the American physicist Arthur Compton (1892-1962) discovered a similar and at first inexplicable phenomenon in his experiments with the effects of scattered 
$X$-rays on graphite crystals. He discovered that the wavelength of the scattered $\mathrm{X}$-rays was longer than that of the incident $\mathrm{X}$-rays; this means that these $X$-rays were lower in energy than the incident ones (the energy of electromagnetic rays is inversely proportional to their wavelength). But if the X-rays emitted from the graphite crystal had a lower energy than the irradiated rays, then they must have lost energy when they were scattered, or they must have transferred something to the crystal. Compton then postulated, similar to Albert Einstein before him, that X-rays consisted of particle-like "X-ray photons" and that the process of scattering in the crystal was comparable to the classical impact of two billiard balls: the incident particle (X-ray photon) hits a resting particle of the crystal (electron) and pushes it away by energy transfer. The energy gain of the electron manifests itself in its acceleration and the energy loss of the X-ray photon in its wavelength lengthening. And a little later Charles Wilson (1869-1959) actually succeeded in detecting electrons pushed away by X-rays using a cloud chamber he had developed. Now the quantum nature of X-rays was also proven and in 1927 both Arthur Compton and Charles Wilson received the Nobel Prize in Physics for this discovery.

However, despite all the medical successes, from the physician's standpoint one was faced with a seemingly insurmountable limitation: X-ray photography is a pure projection process, i. e. as an X-ray beam passes through the body, the shadows of all anatomical structures in the beam path add up to a single overlay image. To overcome this limitation, in 1930 Alessandro Vallebona (1899-1987) developed a method for recording cross-sectional images, known as tomograms. In this process, now known as classic X-ray tomography, the X-ray tube and film are shifted with respect to each other during the exposure, which results in a sharp image only of the structures located at a certain depth. All structures above and below it are reproduced blurred and contribute to the image only in the form of a featureless haze. This made it possible for the first time to obtain slice images of the inside of the body, i. e. structures in the depth of the body could be displayed without superimposition.

The 1970 s saw a groundbreaking success. Godfrey Newbold Hounsfield, a British electrical engineer employed by EMI, had developed a new method of imaging with $\mathrm{X}$-rays based on the theoretical preliminary work of the American physicist Allan Cormack (1924-1998) in 1963/4. Cormack was a hospital physicist at Groote Schuur Hospital in Cape Town who was working on a method to improve radiotherapy planning, which involved quantitative transmission measurements in narrow cross-sectional volumes to quantitatively measure absorption coefficients [23]. Hounsfield had developed his main concepts of a scanner in 1967-68, but didn't publish his breakthrough until 1972. He also started with transmission measurements, using radioisotopes as radiation sources. He performed a large number of such measurements from different spatial directions from a full 180 degrees and with a computer calculated superposition-free sectional images, or tomograms, from the totality of the measured values. Initially, it took nine days to collect the data (about 28000 measurements) and two and a half hours of computing time to reconstruct the image. Consequently his method was christened "computed tomography”. The computer was vital in this process, since tomo- grams could be calculated or reconstructed from the data of the various spatial directions using certain calculation algorithms. At that time the development of computers was still in its early stages. Only shortly before, in 1965, the Olivetti company had launched the world's first freely programmable desktop computer, the "Programma 101" [24]. Hounsfield had already been involved in the development of the first all-transistor computer built in the UK, the EMIDEC 1100, back in 1958. His special interests and skills in computer science were an important foundation for the development of CT. This initial application of new computer technology to medicine was undoubtedly groundbreaking.

Naming this technology, however, overshadowed the other, but quite crucial, innovation of the new process: visualization of the $\mathrm{X}$-rays was no longer done visually by blackening an X-ray film, but purely electronically by converting the $X$-rays into electricity, which, quantitatively registered, provided the digital numerical input for the computer. Using electrical detectors, absorption of the X-rays was thus no longer only qualitatively imaged but also quantitatively measured. The development of CT thus also marked the transition from film-based analog to detector-based digital X-ray photography. In the first EMI brain scanner (EMI Mark 1), two detectors arranged next to each other and $5 \times 13 \mathrm{~mm}$ pixels were mounted opposite the $\mathrm{X}$-ray tube in order to record two layers at the same time, i.e. 1 pixel per layer (this was also the first multi-slice CT) ( $\triangleright$ Fig. 7). The detector material consisted of a sodium iodide scintillation crystal in which the incident $\mathrm{X}$-rays generated visible light through absorption, which in turn was converted into an electrical current in a downstream photomultiplier, registered and digitally transformed. The measurement times were initially around nine days, which were then shortened to nine hours using powerful X-ray tubes. The first CT scan of a person on October 1, 1971 marks a milestone in medical imaging with X-rays with a groundbreaking influence on medical diagnostics. Atkinson Morley's Hospital in London was the site of the first clinically-employed CT system in 1971. This allowed overlay-free cross-sectional images of the brain of a woman with a hemorrhaged mass to be recorded with a measurement time of about five minutes per slice $[25,26]$. Introduction of this technology met tremendous enthusiasm in the medical community. Hounsfield and Cormack jointly received the Nobel Prize in Medicine in 1979 for this invention.

The solid-state scintillator Nal was initially used for CT technology. Soon, however, an increasing number of detectors were needed to produce better and artifact-free images as well as to reduce the load on the X-ray tube. Initially, gas detectors were also used, which had high sensitivity and stability if they were large enough and had sufficient gas pressure (up to about 20 bar). These were ionization chambers filled with the noble gas xenon, in which penetrating $\mathrm{X}$-rays ionized the gas atoms, and the electrons released could be registered as current [27]. This technology was abandoned at the beginning of the $1980 \mathrm{~s}$, as improved solidstate detectors and photomultipliers made it possible to achieve higher sensitivity and resolution.

The door to the new world of digital X-ray imaging was opened when the analog blackening of X-ray films was replaced by the digital measurement of currents. Even 50 years before the current rapid development started, radiologists were thus also pioneers 


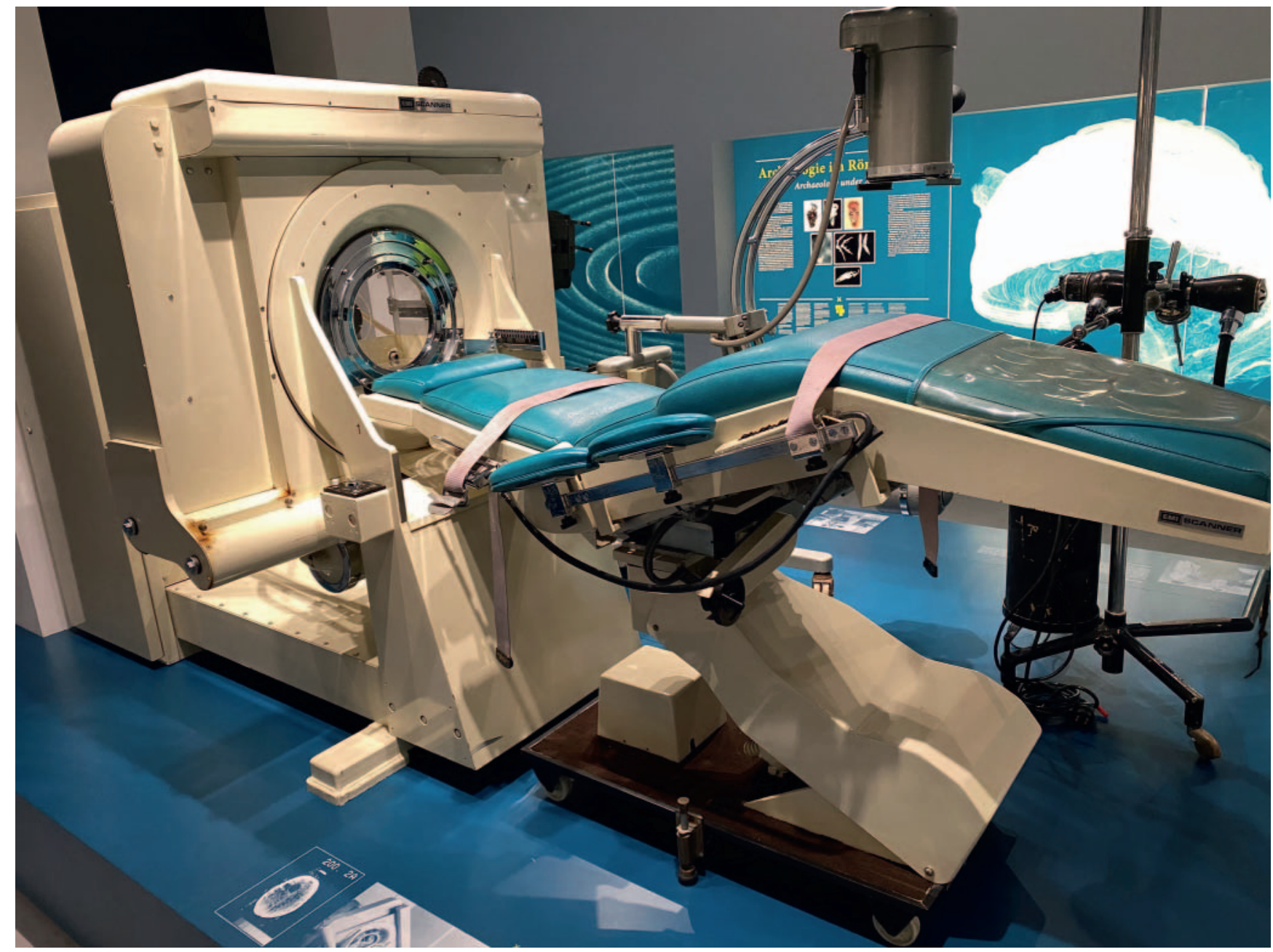

- Fig. 7 EMI Mark I. First clinically-employed and commercially-available CT system installed in 1971, in Atkinson Morley's Hospital in London.

(৫) Deutsches Röntgen-Museum Remscheid). [rerif]

in the digitization of medicine. The first patent for conventional digital X-ray imaging was filed by Eastman Kodak in 1973. The digital Picture Archiving and Communicating System (PACS) was developed in the $1970 \mathrm{~s}$, and X-ray images could thus be archived in a space-saving manner and managed effectively. Gradually the large picture archives with their vast quantities of bulging picture bags were emptied and replaced by large air-conditioned rooms with vast numbers of computer racks. The almost unlimited possibilities of digital image visualization and image post-processing became accessible to radiology, such as calculating quantitative image parameters from individual images or image stacks, to today's state-of-the-art "Big Data" radiomics analyses and artificial intelligence (Al) applications. And nowadays the global communication of images by means of teleradiology, with which even large amounts of data can be transmitted over long distances in the shortest possible time, is a given.

And again, the development of medical X-ray imaging was closely related to the development of photography, as common film cameras were completely replaced by digital cameras. This new type of photography has the great advantage that immediately visible images are created without the need for a prior tedious chemical development process. Images can be stored, managed and sent digitally with high efficiency. In addition, the whole range of options for digital image post-processing is available, recently also Al-based features such as face recognition. Digital photography and digital X-ray imaging are based on the use of flat detectors in which incident electromagnetic radiation releases electrons that flow off in an electric field and are subsequently registered. For physical and technical reasons, CCD (Charged Couple Device) detectors are used for digital photography and CMOS (Complementary Metal Oxide Semiconductor) or aSi-TFT (amorphous Silicon-Thin Film Transistor) detectors are primarily used for digital $\mathrm{X}$-ray imaging. It is interesting to note that the transition from analog to digital $\mathrm{X}$-ray imaging in the radiological practice took place earlier than in photography. Even though the development of digital photography took place at about the same time, the first digital camera with CCD sensors was presented at CeBIT in 1991 (Dycam Model 1). In the meantime, even flat cell phones are equipped with high-resolution cameras, the detectors or "sensors" of which contain up to 100 million pixels (100 megapixels) of about $1 \mu \mathrm{m}$ in size on an area of only about $25-50 \mathrm{~mm}^{2}$. 
The flat panel detectors are for X-ray imaging what camera sensors are for digital photography. Digital X-ray detectors for medical applications function along a similar principle, but use different materials due to the higher energy of the X-rays. The approximately $45 \mathrm{~cm}$-large flat panel detectors of conventional $X$-ray imaging systems contain between $2000 \times 2000$ and $3000 \times 3000$ pixels, each about $140-200 \mu \mathrm{m}$ in size. Digital data acquisition also makes it possible to record sequential image series with flat panel detectors rotating around the patient and to calculate slice images from them using image reconstruction methods of computer tomography. The process was named cone-beam $C T$, even though the fan beams illuminating the flatpanel detector were actually more pyramidal in shape (the lines of the CT scanner, on the other hand, are struck by a line-shaped beam). Today, cone-beam CT has significant clinical applications in interventional radiology and radiation therapy. A very good insight into the development of digital radiography can be found in [28].

Clinical CT systems use indirect detectors [29, 30]. These detectors are also referred to as energy integrating detectors (EID) or charge integrating pixel arrays, in which each pixel element consists of a flat layer of scintillator material (in CT usually gadolinium oxysulfite, $\mathrm{Gd}_{2} \mathrm{O}_{2} \mathrm{~S}$ ), photodiode and, depending on the design, integrated electronics. The incident $\mathrm{X}$-rays generate visible light in the scintillator material, activating electrons in the underlying photodiode, which in turn are registered as current by the underlying electronics. The term "energy integrating" is used because the currents induced by the X-ray photons in the photodiodes have a relatively long half-width. In electronics, the electron shower generated by an X-ray photon does not induce an instantaneous current signal, but rather one that is extended in time and develops in a bell-shaped manner. The time span halfway from its maximum is called the half-width. Long half-widths therefore produce signal curves that are longer over time, which inevitably means that the signals of $X$-ray photons arriving in quick succession overlap and thus accumulate in the detector. The measured detector signal therefore does not represent the energy of individual, but rather the integrated energy of several X-ray photons arriving in quick succession. But EIDs are nonetheless extremely powerful and are currently used in all spiral CT clinical systems. With EIDs, a low-dose CT of the lung can be obtained with only about 0.1 to $0.2 \mathrm{mSv}$, which is on the order of the dose of a conventional X-ray chest radiograph in two planes. A 3D examination of the entire heart can be performed with a dose of less than $0.5 \mathrm{mSv}$. Clinical CT systems with higher resolution of up to $0.15 \mathrm{~mm}$ are also commercially available (Canon/Toshiba Medical Systems). In principle, even higher resolutions can be achieved with EIDs, and small-animal CTs with EIDs achieve resolution into the $\mu \mathrm{m}$ range. However, EIDs are indirect detectors, and sensitivity, image resolution and image sharpness are limited by the scatter of the scintillator light generated by the X-ray photons. The blurring can be reduced with a thinner scintillator layer, but less scintillator material also means less scintillator light, which in turn reduces the sensitivity of the detectors and consequently increases the dose requirement. Al-based image reconstruction methods can partially control the higher image noise, allowing higher spatial resolutions valuable for diagnostics, especially for high-contrast objects such as the lung, bone, or contrast-filled vessels. However, limits are set by the maxim of radiation protection, the ALARA principle (As Low As Reasonably Achievable), which always requires medical applications of ionizing radiation to critically weigh the radiation dose administered against the actual medical benefit.

In the 1980 s, EID was the first step towards color vision, i.e. the implicit recording of different $\mathrm{X}$-ray energies to differentiate different materials, e. g. kidney stones, or the separation of bones and iodine-based contrast media. Device manufacturers have developed various techniques for this purpose to detect the energy-dependent absorption behavior even with the non-energyselective energy-integrating detectors. This was realized with at least two different energies; this is referred to as a dual-energy CT [31].

- As early as the 1980 s, Siemens implemented fast switching of $\mathrm{X}$-ray voltage, so that the voltage changed several hundred times from a low to a high voltage value during one cycle of the CT system, i. e. every millisecond. However, due to the low tube output at that time, the concept did not catch on. About 10 years ago, General Electrics implemented this process with rapid switching between a high $(140 \mathrm{kV})$ and a low $(80 \mathrm{kV})$ tube voltage for clinical CT systems (rapid kV switching).

- About 15 years ago Siemens implemented a two-spectra CT with a dual-source dual-energy system. Data acquisition takes place simultaneously with two X-ray tubes (dual-source) offset at an angle of $90^{\circ}$, which are operated with two different tube voltages (dual-energy), high (e. g. $140 \mathrm{kV}$ ) and low (e.g. $80 \mathrm{kV}$ ). Two-tube technology was primarily developed to reduce the time resolution for cardio CT images to a quarter of the rotation time of the gantry; the simultaneous operation of both $\mathrm{X}$-ray tubes at different voltages also enables the acquisition of energy-selective data sets.

- The third development of a dual-spectrum CT was realized by Philips and consists of an X-ray tube and a two-layer, so-called sandwich detector (dual-layer scintillation detector), in which each pixel is composed of two energy-integrating detector pixels mounted on top of each other. In this case, it is not the tube voltage but the detector absorption that determines the energy selectivity. The upper detector pixel absorbs primarily low-energy photons and is accordingly sensitive to the lower energy range, whereas the lower detector pixel primarily absorbs higher energy photons and is sensitive to the higher energy range.

- Another, more cost-effective realization of dual-spectrum CT is split-filter technology, in which there are two different prefilters on the tube side that separate the X-ray beam into a low and a high energy component (“TwinBeam", Siemens Healthineers). The filter system is designed in such a way that the first pre-filter separates the first half of the detector rows and the second prefilters the other half, whereby the first half of the rows record a low-energy and the second half a higher-energy X-ray spectrum.

- The technology from Toshiba / Canon Medical Systems dispenses with the special hardware of the CT system. A largevolume examination area is examined twice in quick succession by means of successive rotations at different tube voltages $(135 \mathrm{kV}$ and $80 \mathrm{kV})$. The short time difference between the 


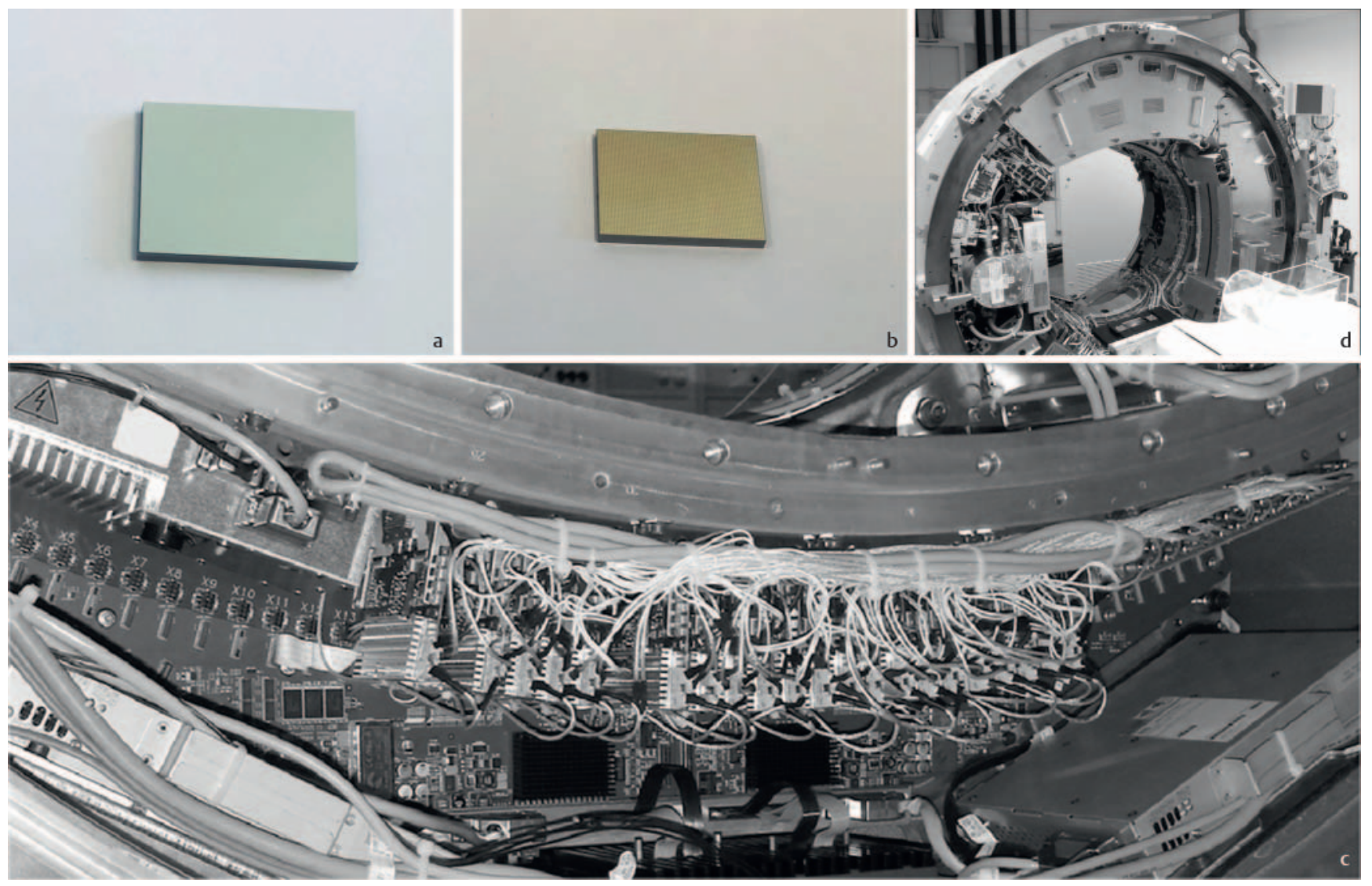

- Fig. 8 Components of a photon-counting detector (courtesy of Kurt Stadlthanner and Thomas Flohr, Siemens Healthineers). a, b $18 \times 15$ mm $\mathrm{CdTe}$ sensor with a bare top surface where the X-rays strike and $\mathbf{b} 64 \times 64$ pixellated bottom surface. Each of the 4096 detector elements registers the electron cascades created in the GdTe, whose path is defined by a strong electric field between the cathode on top and the pixellated anodes on the underside. c Sensor board with electronics with $2 \times 30$ sensors, corresponding to $128 \times 1920=245760$ subpixels (the retina of the eye has about 120 million "pixels", i. e. about 500 times as many). The measuring field of the detector is $22 \mathrm{~cm}$ in the isocenter. $\mathbf{d}$ Detector arrays in the gantry of a prototypical dual source CT scanner. The detector array at the top of the image is a photon-counting cadmium telluride (CdTe) detector (see a, b), and the detector array on the right of the image is a conventional energy-integrating gadolinium oxysulfide $\left(\mathrm{Gd}_{2} \mathrm{O}_{2} \mathrm{~S}\right)$ detector.

scans corresponds to the duration of one gantry rotation, which limits possible artifacts due to patient movement and different contrast agent distributions.

The further advancement of X-ray detectors culminated in photon-counting detectors (PCD), which - as the name suggests register individual $\mathrm{X}$-ray photons separately and can also assign their respective energy to specific sub-areas. This technology was based on large-scale experimental particle physics research during the $1980 \mathrm{~s}$, which required ever-larger detectors with smaller pixels, more sensitive detector materials, and increased microelectronics integration densities to increase the spatial resolution and energy resolution of beams. PCD pixels have a two-layer structure with a detector material (in CT usually cadmium-telluride-(zinc)) facing the X-ray beam, in which the incident X-ray photons ionize, i. e. release electrons, as well as adjacent microelectronics that register these electrons. Each individual X-ray photon generates a cloud of electrons proportional to its energy, which is directed along a high-voltage field to the anode and registered there as an event with a specific amount of charge. The quantitative measurement of the amount of charge, and thus the energy of the respective X-ray photons, is carried out in stages using several energy thresholds, called energy bins (continuous measurement would disturb the time resolution). Using $\mathrm{PCDs}, \mathrm{X}$-ray photons can therefore be counted and their energy determined in relation to predefined threshold values. Compared to EIDs, PCD technology offers numerous advantages:

1. PCDs have a higher energy yield than EIDs. The electrons released by the X-rays are registered directly by the anode without any detours, whereas the scintillator light induced in the EID is partially lost by scattering even before registration by the photodiode.

2. PCDs do not generate perceivable electronic noise because the lowest measurement threshold for registration is set above the signal strength of the electronic noise. The signal-to-noise ratio (SNR) of the PCD is thus higher than that of the EID.

3. With higher energy yield and better SNR, PCDs have improved dose efficiency, thus reducing dose.

4. A higher spatial resolution can be achieved with PCDs. The PCD pixel area has to be even smaller compared to the EID in order to register individual $\mathrm{X}$-ray photons separately (the edge length is approx. $225 \mu \mathrm{m}$ ). With the usual flow rates of clinical CT sys- 

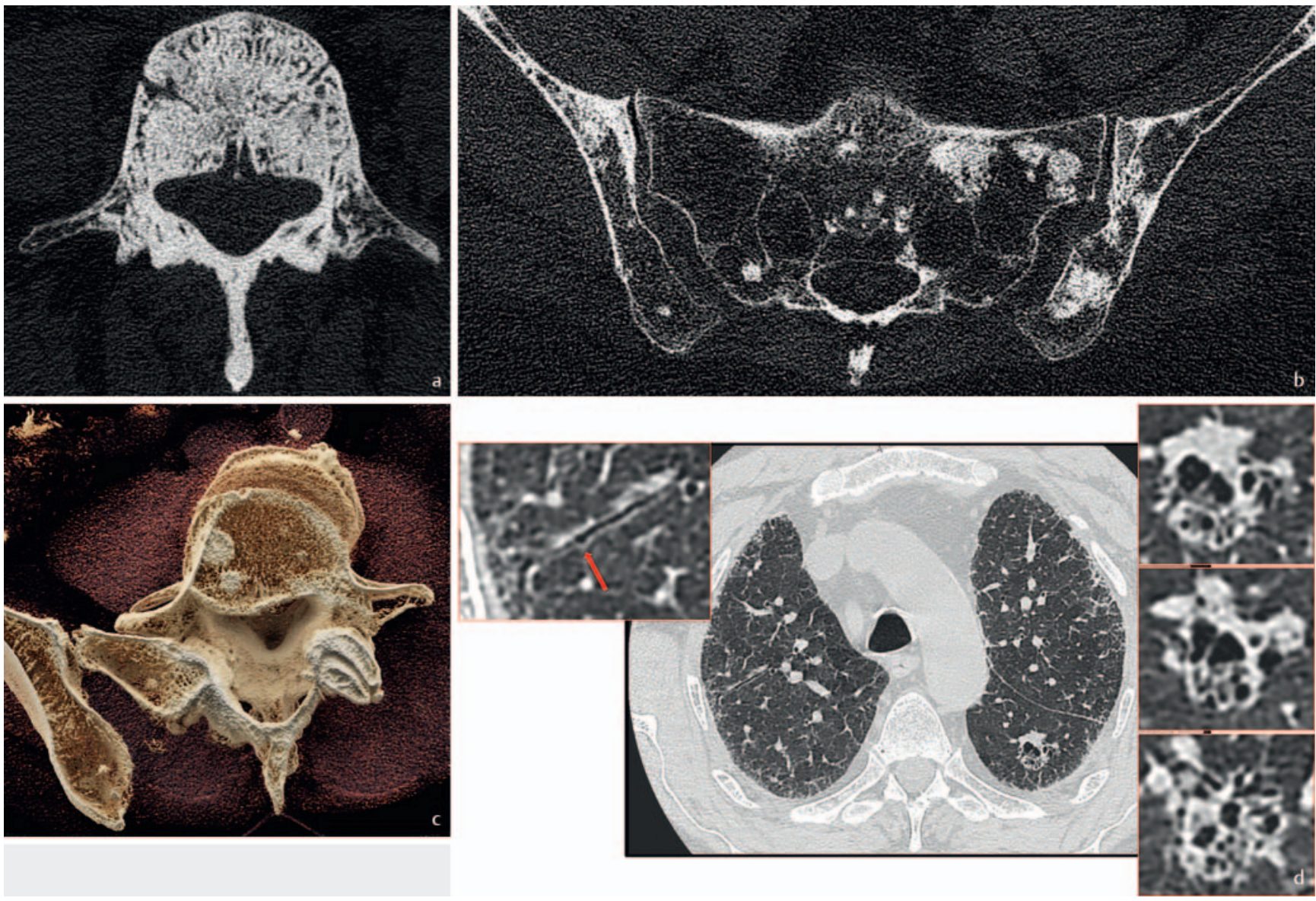

> Fig. 9 Photon-counting CT (DKFZ [38, 39], CT system "SOMATOM CounT" prototype, Siemens Healthineers, Forchheim), 120 kV, 300 mAs, CTDI_vol $24 \mathrm{mGy}$, a-c Imaging of bone with UHR U70F, $0.27 \times 0.27 \times 0.25 \mathrm{~mm}^{3}$. a Osteoblastic metastasis of a patient with prostate carcinoma; b Osteolysis and endosteal scalloping of a patient with myeloma. The right os ileum also shows the punch channel of the diagnostic bone marrow punch; c Osteoblastic metastases of a patient with breast carcinoma, cinematic rendering (Syngo.via ${ }^{\circledR}$, Siemens) from UHR U70F, $0.27 \times 0.27 \times 3.0 \mathrm{~mm}^{3} ; \mathbf{d}$ Patient with pulmonary fibrosis and questionable pulmonary metastasis of sigmoid carcinoma. UHR I70F,

$0.27 \times 0.27 \times 1.0 \mathrm{~mm}^{3}$. The high-resolution representation shows the right subtle wall changes of a traction bronchiectasis lung as an expression of fibrotic processes (left enlargement) as well as cystic-tubular architectural disorders circumscribed in the left lung without a solid component, which speak against the presence of a lung metastasis (enlargement on the right), confirmed by a decrease in size during the follow-up.

tems, too many X-ray photons would strike larger pixel areas per time. Signals arriving too soon after one another would then no longer be separable and would pile up. The high dose efficiency of PCDs, however, makes it possible to use even the smaller pixels for imaging (small pixel effectiveness), [32, 33]).

5. PCDs provide spectral resolution. The information can be used for different purposes, e. g. to reduce beam-hardening artifacts [34], to increase soft tissue contrast in the low $\mathrm{kV}$ range and to increase contrast after application of iodine-based contrast media. Measurement in the energy range of the K-edge of different atoms allows the use and specific separation of new contrast agents, such as those based on bismuth (Bi) or gold (Au) $[35,36]$.

The CT detector, the "retina" of the CT, is composed of approx. a quarter-million pixels, each with an area of approx. $0.05 \mathrm{~mm}^{2}$, each consisting of highly sensitive detector material and rapid electronics (128 $\times 1920$ pixels, each $225 \mu \mathrm{m}$ edge length) $(\vee$ Fig. 8a-d). The power of the technology becomes clear when one realizes that about one billion X-ray photons hit one square millimeter of the detector material per second, or the equivalent of about 50 million on one pixel. The temporal resolution for registering individual $\mathrm{X}$-ray quanta is thus on the order of 50 nanoseconds $\left(50 \times 10^{-9} \mathrm{~s}\right)$. However, the separation of individual photons can only succeed if the signal triggered by a photon in the detector has decayed so quickly that it does not pile up with the subsequent signals; this is achieved by using highly sensitive semiconductors with extremely short dead times. In addition, fast electronics are necessary to enable the rapid removal of the generated charges and thus their individual registration. This requires a high-speed readout of approx. $4-8 \mathrm{kHz}$ and a correspondingly high data transmission rate from the detector to the computer, i. e. very rapid data acquisition systems (DAS) are necessary. The data flow can be up to 45000 times that of a television set. This is in addition to the high performance requirements for the downstream computer technology, which, based on the vast amounts of data has to reconstruct the images that we perceive in real time. 


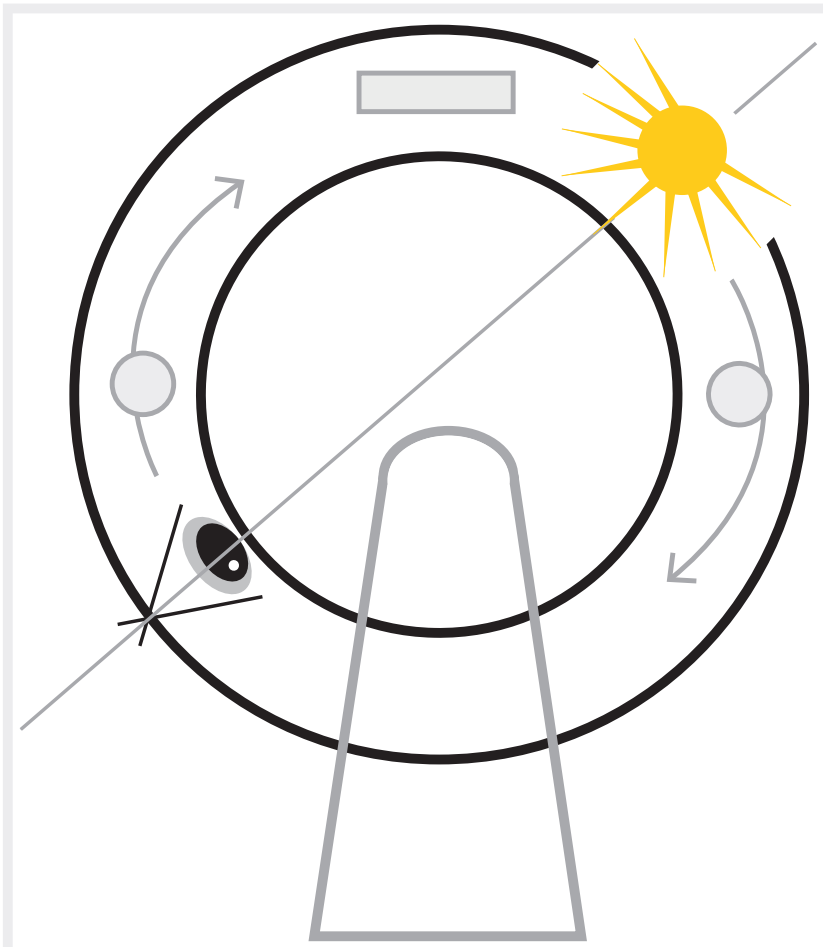

- Fig. 10 "The Eye of the CT Scanner".

Due to their high cost and sophisticated electronics, PCDs have not been used for clinical CT scanners. However, the advantages described above suggest clinical applications.

- The higher dose efficiency supports dose reductions and thus opens up a broad clinical field of application, including for children and obese patients in general or for special applications such as cardio $C T$, sequential oncological whole-body CTs or lung cancer screening.

- Spectral resolution can be used for different purposes, e. g. to reduce beam-hardening artifacts, to increase soft tissue contrast and to increase contrast after application of iodine-based contrast media. Reduction in the amount of contrast required would also be possible.

- The higher spatial resolution allows a more detailed visual assessment of morphological changes, e. g. of the lung, bone or vessels.

- Soft tissue contrast is increased at low energies, which can improve tissue differentiation.

- The higher information content generally leads to an improvement in computer-aided shape and texture analyses (radiomics, deep learning/AI).

Initial clinical investigations on experimental systems demonstrated promising results. ( $\vee$ Fig. 9a-d) [37-43].

The success story of imaging with $\mathrm{X}$-rays is the result of the mutual enrichment of physics, medicine, mathematics, computer science, engineering and entrepreneurial skill. Ongoing research and development of precise methods for the detection of X-rays began with the visual observation of luminous fluorescent screens and photographic plates, and in little more than 100 years has led to the computer-assisted quantitative analysis of individually registered X-ray photons. The detector array of the CT scanner is like the retina of the eye ( $\nabla$ Fig. 10 ). The continuously refined non-invasive insight into the body is groundbreaking for the advancement of medicine. But what seems self-evident to us nowadays would have been dismissed as fantasy at the end of the $19^{\text {th }}$ century.

"Methodology is everything" (Otto Warburg, 1923) [44].

\section{Conflict of Interest}

The authors declare that they have no conflict of interest.

\section{Acknowledgments}

I would like to thank Dr. Uwe Busch, Director of the German Röntgen Museum in Remscheid, for his critical review of the manuscript and for kindly providing the illustrations from the archive of the German Röntgen Museum. My special thanks also go to Prof. Marc Kachelrieß, Head of the Dept. of X-Ray Imaging and Computed Tomography at the German Cancer Research Center for his expert review and many valuable suggestions. I would also like to thank the unknown reviewer for the helpful hints that have contributed to the improvement and polishing, especially the last part of the paper.

\section{References}

[1] Ludwig Zehnder (Hrsg). Briefe an L. Zehnder, Rascher \& Cie A.G. Zürich, 1935: 39

[2] Glasser O. Röntgens Entdeckung in der Tagespresse und in populären Zeitschriften. Röntgenstrahlen und Stein der Weisen, Vivisektion, Temperenzbewegung, Spiritismus, Seelenphotografie, Wahrsagerei und Telepathie. In: Wilhelm Conrad Röntgen und die Geschichte der Röntgenstrahlen Berlin, Heidelberg: Springer; 1995. doi:10.1007/978-3-64279312-7_6

[3] Walter K. Pioniere und Opfer der Röntgenstrahlen. Zum Gedenken an Gustav Kaiser. In: Röntgen- und Laboratoriumspraxis 10 1957: 35ff

[4] Beneke K. Wilhelm Conrad Röntgen und die Entdeckung der Röntgenstrahlen. In: Beiträge zur Geschichte der Kolloidwissenschaften, VII. Mitteilungen der Kolloid-Gesellschaft Nehmten: Verlag Reinhard Knof ISBN: 3-9804010-9-X

[5] Briefdokument Coolidge WD an seine Mutter, Leipzig 26.11.1898. Archiv Deutsches Röntgen-Museum

[6] Röntgen WC. Über eine neue Art von Strahlen; Vorläufige Mittheilung; 1895: Aussage 6

[7] Schedel A, Keil R. Der Blick in den Menschen: Wilhelm Conrad Röntgen und seine Zeit. München, Wien, Baltimore: Urban und Schwarzenberg; 1995. ISBN: 3-541-19501-0

[8] Heuck FHW, Macherauch E Hrsg Forschung mit Röntgenstrahlen. Bilanz eines Jahrhunderts. Berlin, Heidelberg, New York, London, Paris, Tokyo, Hong Kong, Barcelona, Budapest: Springer; 1995. ISBN: 3-540-57718-1

[9] Kumar M. Quanten. Berlin: Berlin Verlag GmbH; 2009: 25

[10] Die Ära der Röntgenstrahlen. 9 Spektrum der Wissenschaft; 1995: 88 https://www.spektrum.de/magazin/die-aera-der-roentgenstrahlen/ 822531

[11] Simonyi K. Kulturgeschichte der Physik. 3. Aufl. Verlag Harri Deutsch; 2001: $381 \mathrm{ff}$

[12] Busch U. Erster Strahlenunfall: Verpasste Lorbeeren oder der erste Strahlenunfall der Geschichte. Website der Deutsche Röntgengesellschaft. https://www.drg.de/de-DE/2365/erster-strahlenunfall/ 
[13] Schedel A, Keil R a.a.O.: $11 \mathrm{ff}$

[14] Röntgen WC a.a.O.: Aussage 1

[15] Osterhammel ]. Die Verwandlung der Welt. Eine Geschichte des 19. Jahrhunderts. C. H. Beck. 2 Aufl. der Sonderausgabe 2016. ISBN: 978-3406-61481-1S. 77

[16] Brit J Photography 1896; 43: 26

[17] Schedel A, Keil R a.a.O.: 134

[18] Röntgen WC a.a.O.: Aussage 12

[19] Ebda. Aussage 17.

[20] https://en.wikipedia.org/wiki/Heinrich_Hertz

[21] Schedel A, Keil R a.a.O.: 137ff

[22] Degenhardt H. Zur Verwendung von Seltene-Erden Leuchtstoffen in feinzeichnenden Verstärkerfolien. Elektromedica 1980; 48: 76-79

[23] Cormack AM. Representation of a function ba its line integrals, with some radiological applications, J. Appl Physics 1963; 34: 2722

[24] Dette K. Olivetti Personal Computer fur Lehre und Forschung. Springer, 1989; Brennan, AnnMarie: Olivetti: A work of art in the age of immaterial labour. Journal of Design History 2015; 28: 235-253; Tischcomputer. In: kuno.de

[25] Hounsfield GN. Computerized transverse axial scanning (tomography) Part I. Description of the system. Br J Radiol 1973; 46: 1016-1022

[26] Bates S, Beckmann L, Thomas A. Godfrey Hounsfield: Intuitive Genius of CT (Englisch) Gebundene Ausgabe - 26. April 2012.

[27] Goldman LW. Principles of CT and CT technology. J Nucl Med Technol 2007; 35: 115-128

[28] Heuser L. Digitale Radiografie - Geräte und Methoden. In: Kramme R, (Hrsg) Medizintechnik. Springer Reference Technik. Berlin, Heidelberg: Springer; 2015. doi:10.1007/978-3-662-45538-8_17-1

[29] Panetta D. Advances in X-ray detectors for clinical and preclinical Computed Tomography. Nuclear Instruments and Methods in Physics Research A 2016; 809: 2-12

[30] Lell MM, Kachelrieß M. Recent and Upcoming Technological Developments in Computed Tomography: High Speed, Low Dose, Deep Learning, Multienergy. Invest Radiol 2020; 55: 8-19

[31] McCollough CH, Leng S, Yu L et al. Dual- and Multi-Energy CT: Principles, Technical Approaches, and Clinical Applications. Radiology 2015; 276 : 637-653. doi:10.1148/radiol.2015142631

[32] Kachelrieß M, Kalender W. Medical Physics 2005; 32: 1321-1334
[33] Klein L, Dorn S, Amato C et al. Effects of Detector Sampling on Noise Reduction in Clinical Photon-Counting Whole-Body Computed Tomography. Invest Radiol 2020; 55 (2): 111-119. doi:10.1097| RLI.0000000000000616

[34] Byl A, Klein L, Sawall S et al. Photon Counting Normalized Metal Artifact Reduction in 1 Diagnostic CT Submitted to Medical Physics, under review.

[35] Sawall S, Klein L, Amato C et al. lodine contrast-to-noise ration improvement at unit dose and contrast media volume reduction in wholebody photon counting CT. Eur J Radiol 2020; 126: 108909. doi:10.1016/ j.ejrad.2020.108909

[36] Amato C, Klein L, Wehrse E et al. Potential of contrast agents based on high-Z elements for contrast-enhanced photon-counting computed tomography. Med Phys 2020. doi:10.1002/mp.14519. Online ahead of print. Med Phys. 2020. PMID: 33011992

[37] Flohr T, Ulzheimer S, Petersilka M et al. Basic principles and clinical potential of photon-counting detector CT. Chin J of Acad Radiol 2020; 3: 19-34

[38] Leng S, Bruesewitz M, Tao S et al. Photon-counting Detector CT: System Design and Clinical Applications of an Emerging Technology. Radiographics 2019; 39: 729-743

[39] Willemink M], Persson M, Pourmorteza A et al. Photon-counting CT: Technical Principles and Clinical Prospects. Radiology 2018; 289: 293312

[40] Pourmorteza A, Symons R, Henning A et al. Dose Efficiency of QuarterMillimeter Photon-Counting Computed Tomography: First-in-Human Results. Invest Radiol 2018; 53: 365-372

[41] Klein L, Dorn S, Amato C et al. Effects of Detector Sampling on Noise Reduction in Clinical Photon-Counting Whole-Body Computed Tomography. Invest Radiol 2020; 55: 111-119

[42] Wehrse E, Klein L, Rotkopf L et al. Photon-Counting Detectors in CT: From Quantum Physics to Clinical Practice. Der Radiologe 2021; Online First. doi:10.1007/s00117-021-00812-8

[43] Wehrse E, Sawall S, Klein L et al. Potential of Ultra-High-Resolution Photon-Counting CT of Bone Metastases: Initial experiences in Breast Cancer Patients. npj Breast Cancer 2021; 7 (1): 3. doi: 10.1038/s41523-02000207-3

[44] Warburg O. Versuche an überlebendem Carcinomgewebe: Methoden II: Die Herstellung der Gewebeschnitte. Biochem Z 1923; 42: 317-333 